\title{
Finite element analysis in bone structure around implants with different geometries
}

\author{
Danilo Martho (IC), Alexandre R. Freire (PQ), Roberta Okamoto (PQ), Ana Cláudia Rossi (PQ), Felippe \\ B. Prado (PQ). \\ Abstract \\ This study presented a finite element analysis of axial and oblique forces simulation in bone/implant system \\ according different bone densities and two different implant geometries. The stress was changed according \\ cortical bone thickness and internal implant structure with geometries.
}

Key words: finite element analysis, implant, bone.

\section{Introduction}

The initial bone density does not only provide a mechanical restraint of the implant during healing, but also enables the distribution and transmission of stresses (after healing) of the prosthesis to the bone / implant interface. The mechanical stress distribution occurs mainly on the bone contact with the implant ${ }^{1}$.

For analysis of the distribution and transmission of stress from implants to bone structure, a finite element analysis has been used ${ }^{2}$.

The aim of this study was evaluated the distribution of stress transmitted to different bone densities (D1, D2, D3 and D4) around prosthetic implants with different geometries by finite element analysis.

\section{Results and Discussion}

In this study, we observed that the distribution of stresses between the two types of implant geometries (external hexagon and Morse taper) in bone D4, in which the cortical bone is thinner and, consequently, is more sensitive to the loads. Furthermore, the smallest thickness of cortical bone resulting in the positioning of the first threads in the cancellous bone, in which experimentally the process of bone remodeling is less intense ${ }^{3}$.

The external hexagon implant tends to make more intense stimulation in bone structure, particularly in the bones type D3 and D4. In both, the axial and the oblique forces, the bone density changed in the morphological point of view, characterized by decreased cortical and increased trabecular bone, tend to result in more intense stresses, particularly in regions close to the prosthetic connector.
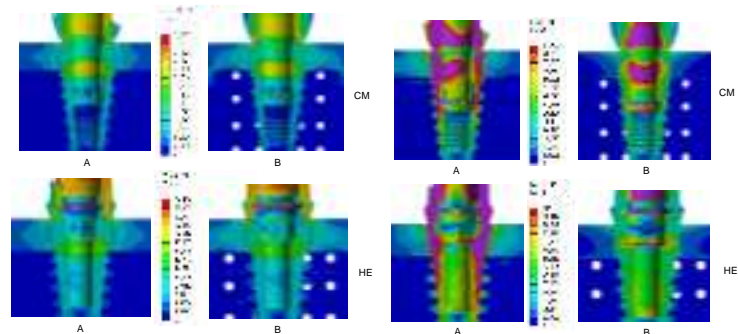

Image 1. Examples of finite element simulations in D4 bone density. Left: Axial load. Right: Oblique load.

\section{Conclusions}

Variations of the type of implants (External hexagon and Morse Taper) and direction of the forces (axial and oblique forces) influencing the distribution of stresses transmitted to around of prosthetic implant.

\section{Acknowledgement}

The authors are grateful to the National Counsel of Technological and Scientific Development (PIBIC-CNPq) for financial support.

\footnotetext{
${ }^{1}$ Gargallo, A.J.; Satorres-Nieto, M.; Puyuelo Capablo, J.L.; Sanchés Gárces, M.A.; Pi Urgell, J.; Gay Escoda, C. Med Oral Patol Oral Cir Bucal. 2008, 13(2), E124-E128.

2 Pessoa, R.S.; Muraru, L.; Marcantonio-Júnior, E.; Vaz, L.G.; Vander Sloten, J.V.; Duyck, J.; Jaecques, S.V.N. Clin Implant Dent Relat Res. 2010, 12(3), 219-234.

${ }^{3}$ Misch CE. Divisions of available bone in implant dentistry. Int J Oral Implantol. 1990, 7(1), 9-17
} 